\title{
Males with Obesity and Overweight
}

\author{
Kyoung-Bae Kim', Yun-A Shin ${ }^{2 * *}$ \\ ${ }^{1}$ Department of Physical Education, Korea Military Academy, Seoul; ${ }^{2}$ Department of Prescription and Rehabilitation of Exercise, College of Sport Science, Dankook \\ University, Cheonan, Korea
}

Global average data suggest that the prevalence of obese and overweight males is much higher than that of females in some regions. The gender gap in obese and overweight individuals has deepened in many countries, and the gap is more prominent in overweight than in obesity. In particular, the prevalence of male obesity has continuously increased in the Republic of Korea over the past two decades, whereas the increase in female obesity has slowed and may even have plateaued. The cutoff point for obesity in Korea is a body mass index of $\geq 25 \mathrm{~kg} / \mathrm{m}^{2}$, which is equivalent to the international classification of being overweight. Researching obesity in males is not as prevalent as studying obesity in females. Previous studies have rarely considered obesity type (android vs. gynoid), hormones (testosterone, androgen, etc.), awareness of body shape, or special resources such as exercise interventions to improve male weight issues. Adaptations to exercise interventions show individual variability as well as differences between men and women. Therefore, integrated approaches to research should be adopted, including evaluation of socio-demographic and physiological characteristics, to ensure that such interventions are not simply a symptomatic treatment but are actually treating the root cause of the obesity.

Key words: Male, Obesity, Gender, Exercise

\author{
Received January 14, 2020 \\ Reviewed January 27, 2020 \\ Accepted February 13, 2020 \\ ${ }^{*}$ Corresponding author \\ Yun-A Shin \\ https://orcid.org/0000-0002-8480-3454 \\ Department of Prescription and \\ Rehabilitation of Exercise, College of \\ Sport Science, Dankook University, \\ 119 Dandae-ro, Dongnam-gu, \\ Cheonan 31116, Korea \\ Tel: $+82-41-550-3830$ \\ Fax: +82-41-440-3831 \\ E-mail: shinagel3@gmail.com
}

\section{INTRODUCTION}

The prevalence of obese and overweight individuals has been increasing worldwide for several decades, despite many efforts to prevent the condition. According to the 2016 Global Health Observatory (GHO) data published by the World Health Organization (WHO), in 2016, 13.1\% of the global population was obese and $38.9 \%$ was overweight, while the equivalent figures in 1975 were $4.7 \%$ and $21.5 \%$, respectively. Furthermore, in 2016, $15.1 \%$ of women and $11.1 \%$ of men aged 18 and over were obese, while $39.2 \%$ of women and $38.5 \%$ of men were overweight; ${ }^{1}$ women showed a higher obesity prevalence than men, although the likelihood of being overweight was about the same between men and women. However, the prevalence and trends by gender differed among countries and regions. In some countries, such as Japan, Korea, China, Germany, France, the United Kingdom, and the Unit- ed States of America, obesity was more prevalent among men, which is in contrast to the worldwide average data. ${ }^{1}$ Also, overweight problems by gender are much greater than obesity.

Previous studies have tended to either consider obesity without distinguishing gender or in women only; male obesity has been a less prevalent research topic. Nonetheless, the prevalence of male obesity is increasing, and men appear reluctant to engage in weight loss intervention programs in spite of properly established links between obesity and health-related diseases. ${ }^{2}$ This reticence may reflect a general failure to recognize gender issues in weight management. ${ }^{2}$ Generally, men are less concerned with their weight status than women, and they lack basic nutrition knowledge. ${ }^{3,4}$

Reducing the weight of overweight adults is an important preventative medicine step as it can help to ensure optimal aging. Being overweight tends to precede obesity, at which point it is more difficult to normalize body weight. In this review, we considered

Copyright (C) 2020 Korean Society for the Study of Obesity

(a) This is an Open Access article distributed under the terms of the Creative Commons Attribution Non-Commercial License (https://creativecommons.org/licenses/by-nc/4.o/) which permits unrestricted non-commercial use, distribution, and reproduction in any medium, provided the original work is properly cited. 
studies with a higher prevalence of overweight men than overweight women, because the gender gap between men and women has deepened. Therefore, the purpose of the present study was to elucidate the current status of overweight males in specific countries, as well as to identify how to improve weight management in overweight and obese males.

\section{GLOBAL TRENDS IN OVERWEIGHT BY GENDER}

In Western populations, adult obesity is defined as having a body mass index (BMI) of $\geq 30 \mathrm{~kg} / \mathrm{m}^{2}$, while being overweight is defined as BMI between 25 and $29.9 \mathrm{~kg} / \mathrm{m}^{2}$. In Asians, adult obesity is defined as having a BMI $\geq 25 \mathrm{~kg} / \mathrm{m}^{2}$, which is equivalent to being overweight by the international definition. This definition for adult Asians was suggested by the WHO in $2000 .^{6}$ However, in 2004, the WHO, despite weight heterogeneity throughout Asian countries, recommended retaining the western definition for all international populations. Even so, many studies from Asia still adopt the lower BMI cutoff as detailed in the 2000 proposal. ${ }^{7}$ For this reason, in the present review, we used the BMI cutoff of $\geq 25 \mathrm{~kg} / \mathrm{m}^{2}$ as defined in Asia, even though other regions only consider this as being overweight.

In 2016, the WHO reported almost no difference in the percentage of overweight men and women. ${ }^{1}$ However, within certain regions and income groups, there were several significant gender differences in the prevalence of overweight men and women. The differences in overweight prevalence by region and gender in 1975 and 2016 are presented in Table 1. The global data showed that the prevalence of overweight women was slightly higher than that of men in both 1975 and 2016. With regards to specific regions, there were consistently more overweight females in Africa, South-East Asia, and the Eastern Mediterranean in 1975, whereas there were slightly more overweight males in the Americas and Europe at that time. In 2016, the gender gap had widened in both directions in these regions. In contrast, in the Western Pacific, there were slightly more overweight females in 1975, but the trend was completely reversed in 2016, with the number of overweight males being slightly higher in 2016.

The income and gender differences in the overweight populations in 1975 and 2016 are presented in Table 2. In 1975, the prevalence of overweight females was consistently much higher than

Table 1. Prevalence of overweight individuals in 1975 and 2016 by WHO region and sex

\begin{tabular}{|c|c|c|c|c|}
\hline \multirow{2}{*}{ WHO region } & \multicolumn{2}{|c|}{1975 Prevalence of overweight individuals (\%) } & \multicolumn{2}{|c|}{2016 Prevalence of overweight individuals (\%) } \\
\hline & Male & Female & Male & Female \\
\hline Global & $20.0(17.6-22.7)$ & $22.7(20.3-25.4)$ & $38.5(36.5-40.6)$ & $39.2(37.3-41.1)$ \\
\hline Africa & $7.9(4.9-12.3)$ & $15.0(11.3-19.3)$ & $22.8(20.1-25.7)$ & $38.8(36.2-41.7)$ \\
\hline Americas & $37.0(32.0-42.2)$ & $36.1(31.5-40.9)$ & $64.1(61.3-66.9)$ & $60.9(58.1-63.8)$ \\
\hline South-East Asia & $4.7(2.7-7.2)$ & $7.0(4.8-9.8)$ & $19.7(16.5-23.1)$ & $24.1(21.0-27.4)$ \\
\hline Europe & $39.1(34.7-44.0)$ & $38.8(34.5-43.5)$ & $63.1(60.7-65.6)$ & $54.3(51.7-56.9)$ \\
\hline Eastern Mediterranean & $19.3(14.7-24.5)$ & $27.6(22.0-33.5)$ & $45.4(42.2-48.7)$ & $52.6(49.6-55.7)$ \\
\hline Western Pacific & $10.1(7.2-13.9)$ & $11.9(8.9-15.4)$ & $33.7(29.3-38.3)$ & $29.6(25.8-33.4)$ \\
\hline
\end{tabular}

Values are presented as median (range). Data from the World Health Organization (WHO) Global Health Observatory (2016). ${ }^{1}$

Table 2. Prevalence of overweight individuals in 1975 and 2016 by World Bank income group and sex

\begin{tabular}{|c|c|c|c|c|}
\hline \multirow{2}{*}{ Income group } & \multicolumn{2}{|c|}{1975 Prevalence of overweight individuals (\%) } & \multicolumn{2}{|c|}{2016 Prevalence of overweight individuals (\%) } \\
\hline & Male & Female & Male & Female \\
\hline Global & $20.7(17.6-22.7)$ & $22.7(20.3-25.4)$ & $38.5(36.5-40.6)$ & $39.2(37.3-41.1)$ \\
\hline Low & $6.6(4.1-10.3)$ & $11.4(8.4-15.1)$ & $19.1(16.5-21.8)$ & $32.0(29.3-34.9)$ \\
\hline Lower-middle & $8.5(6.5-11.0)$ & $13.1(10.7-15.8)$ & $23.9(21.4-26.7)$ & $30.0(27.6-32.6)$ \\
\hline Upper-middle & $17.5(14.2-21.2)$ & $23.7(20.3-27.3)$ & $43.5(40.0-47.1)$ & $42.9(39.9-46.0)$ \\
\hline High & $38.4(34.5-42.5)$ & $32.9(29.4-36.5)$ & $63.0(60.6-65.3)$ & $52.0(49.6-54.4)$ \\
\hline
\end{tabular}

Values are presented as median (range). Data from the World Health Organization Global Health Observatory (2016). ${ }^{1}$ 
the prevalence of overweight males in the low and lower-middle income groups, while the prevalence of overweight males was higher than that of overweight females in the high income group; this gender gap had widened by 2016. In 1975, the prevalence of overweight females was higher than that of overweight males in the upper-middle income group, but the prevalence of overweight males was higher in 2016.

The GHO data showed that in 2016 the prevalence of overweight men was higher than that of women in several countries (Fig. 1). ${ }^{1}$ In 1975, the prevalence of overweight males was higher than that of overweight women in Germany and France, and this gender difference became severe in 2016. In the United Kingdom and United States of America, the gender gap was almost the same in 1975 as in 2016; in both countries, the prevalence of both overweight men and women increased by $20 \%$ or more. The prevalence of overweight females was slightly higher in Japan, Korea, and China in 1975, but by 2016, there were more overweight males, showing an absolute reversal. The difference in overweight prevalence

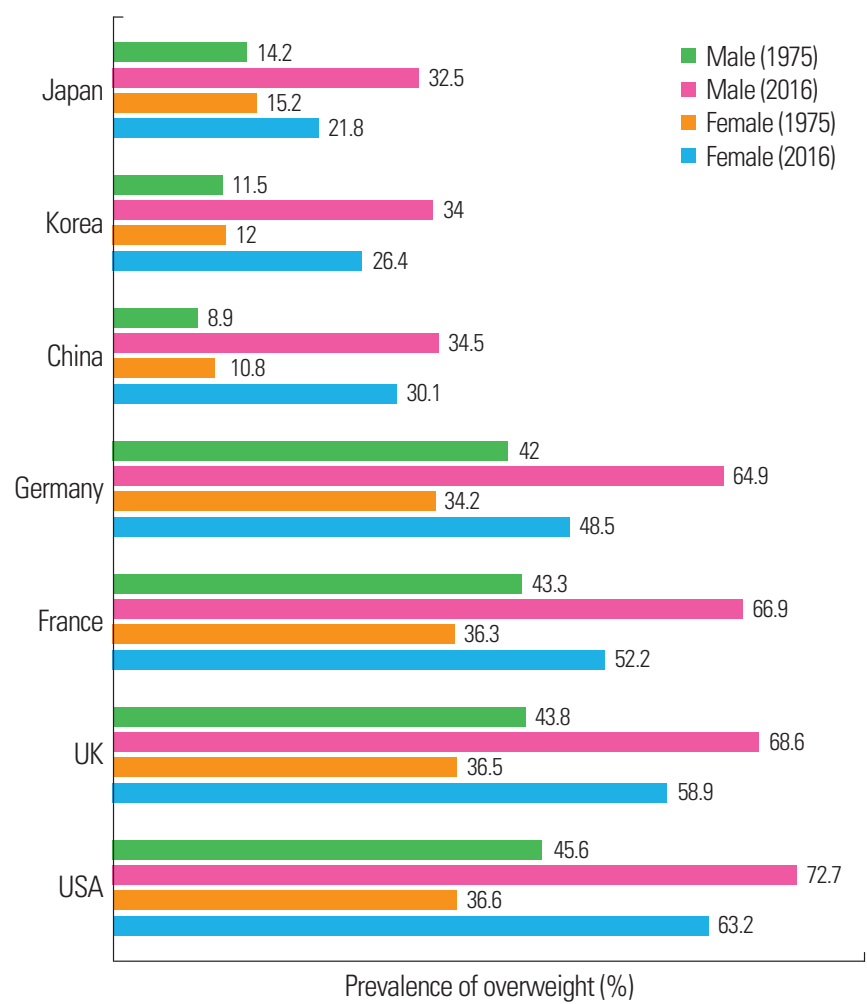

Figure 1. The prevalence of overweight individuals among adults aged $\geq 18$ years in 1975 and 2016 in several nations. The graph is based on the World Health Organization Global Health Observatory data (2016). ${ }^{1}$ between men and women was highest in Japan among these three Western Pacific countries in 2016. The difference in overweight prevalence between 1975 and 2016 among these countries was the highest in China.

\section{OVERWEIGHT AND OBESE MALES IN KOREA}

In the present review, we used data from the Korea National Health \& Nutrition Examination Survey, ${ }^{8}$ which was conducted by the Korea Centers for Disease Control and Prevention in 2017 and adopted the classification of obesity in Asians as stipulated by the WHO in 2000 to analyze overweight and obese males in Korea.

Male obesity prevalence has shown a steady increase over the past two decades in Korea, whereas the increase in female obesity has slowed and may even have plateaued over the same period (Fig. 2). Moreover, in older individuals, the prevalence of obese males is lower, whereas the prevalence of obese females is higher (Fig. 3). Specifically, the male obesity prevalence sharply declines after the age of 50 years, while the female obesity prevalence rapidly increases after the age of 30 years. By the age of 60 years, the obesity prevalence escalated more prominently in women than in men as age increased, although the overall prevalence was higher in men. As stated above, for our current study, we used a BMI of $\geq 25 \mathrm{~kg} / \mathrm{m}^{2}$ as the cutoff for obesity, even though this is considered to be "overweight" according to the international definition (Figs. 2 and 3).

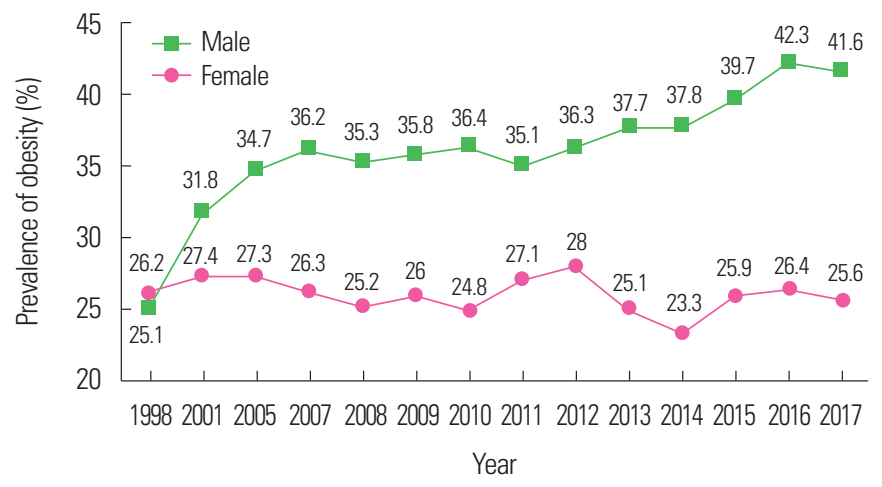

Figure 2. The prevalence trends of adult obesity between 1998 and 2017 in Korea. Data are based on the Korea National Health and Nutrition Examination Survey, which was conducted by the Korea Centers for Disease Control and Prevention in 2017.8 


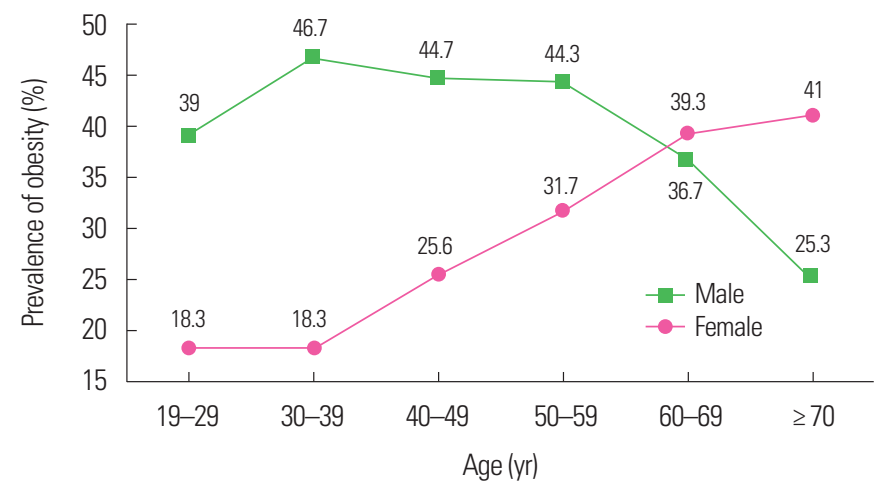

Figure 3. The prevalence trends of adult obesity as age increases in Korea in 2017. Data are based on the Korea National Health and Nutrition Examination Survey, which was conducted by the Korea Centers for Disease Control and Prevention in 2017.8

\section{ANDROID AND GYNOID OBESITY}

Two types of obesity are often distinguished in terms of fat distribution: android (trunk and upper body) and gynoid (lower body, particularly around the hips and thighs). Android obesity leads to an "apple-shaped" body, or central obesity, and is more common in men, whereas gynoid obesity leads to a "pear-shaped" body. The prevalence of cardiovascular and metabolic diseases varies in the different types of obesity within the overall obese group.,10

Adipose tissue function and deposition differs by sex: men accumulate more visceral fat, resulting in the typical android obese body shape, which is highly related to increased cardiovascular risk. Females accumulate more subcutaneous fat before menopause, which plays a protective role against the negative outcomes related to obesity and metabolic syndrome. ${ }^{11}$ Following menopause, fat deposition and accumulation shifts to a more visceral location. This shift leads to a corresponding increase in metabolic risk similar to that seen in men. ${ }^{11}$ According to one study of android and gynoid fat percentages in adults in the United States, local fat deposition features in the android and gynoid patterns have contrasting consequences on lipid profiles, and fat deposits of the android pattern may increase the risk of developing cardiovascular disease. ${ }^{12}$ The type of fat distribution - android or truncal vs. gynoid or peripheral-influences systemic metabolism and hence the risk of obesity complications. ${ }^{13}$

\section{MALE OBESITY AND HORMONES}

The hypothalamic-pituitary-adrenal (HPA) and hypothalamicpituitary-gonadal (HPG) axes influence obesity type, especially the abdominal phenotype. ${ }^{14}$ In both men and women, the HPA response to acute stress ${ }^{15}$ and to central neuroendocrine stimulation $^{16,17}$ tends to be an increase in abdominal and visceral fat deposits. However, the sexual dimorphism seen in obesity may be partly due to differences in the HPG axis. In obese men, testosterone tends to progressively decrease with body weight — an effect caused by reduced gonadotropin secretion, increased leptin, and reduced sex-hormone-binding globulin. ${ }^{18-21}$ On the other hand, women with abdominal phenotype obesity show increased testosterone values. $^{21}$

Men have a tendency to have more central fat deposits during growth from adolescence to young adulthood..$^{22}$ Male androgens play a role in the regulation of adiposity and metabolism. Previous studies have suggested that androgens are inversely associated with fat levels in the visceral and subcutaneous compartments in men. ${ }^{23-25}$ Although testosterone is positively related to maintenance of healthy body composition and lean muscle mass, it also plays an important role in the deposition of fat to different body regions than seen in women. ${ }^{24,25}$ These differences in adipose tissue occur in response to determinants of fat uptake and storage. For example, lipoprotein lipase activity plays a role in limiting the accumulation of fat derived from circulating fatty acids and triglycerides. Lipoprotein lipase activity is higher in abdominal/visceral adipose tissues in men because testosterone suppresses enzyme activity in femoral subcutaneous fat. ${ }^{26}$ On the other hand, enzyme activity is higher in the gluteal/subcutaneous tissues in women. ${ }^{27}$ Therefore, differences in sex hormone levels induce abdominal/visceral obesity in men, while women have more subcutaneous fat but less visceral fat than men. ${ }^{11}$

Intra-abdominal adiposity induces insulin resistance in obese men because they have lower insulin sensitivity, lower adiponectin levels, and higher glucose and leptin levels than obese women. ${ }^{28}$ It may follow that abdominal obesity itself contributes to decreases in circulating testosterone levels ${ }^{29,30}$ given that leptin is negatively related to testosterone levels, ${ }^{20}$ that adiponectin reduces hepatic glucose production, and that increases in hepatic insulin sensitivity are inversely related to insulin resistance and type 2 diabetes mellitus. ${ }^{31}$ 


\section{EFFECT OF EXERCISE/PHYSICAL ACTIVITY BY GENDER}

The benefits of regular exercise and physical activity have been well documented, and exercise therapy is a necessary component of obesity management. However, studies on the effects of exercise mode, duration, and intensity on weight control have shown only small changes or inconsistent results, ${ }^{32}$ especially in the case of visceral adipose tissue. ${ }^{33}$

Previous studies have reported that adaptations to exercise intervention differ between men and women, and that they show individual variability as well. One study reported that the effect of exercise mode (combined aerobic resistance exercise [ARE] vs. aerobic exercise) differs by both gender and body composition. ${ }^{34}$ The same study suggested that ARE in men tends to increase the fat free mass of the arms, trunk, and whole body and to decrease the percentage of fat in the trunk. In women, ARE reduces the fat mass of the legs. Other studies have reported that the effect of physical activity intensity and duration on body composition differs by gender. ${ }^{35,36}$ Specifically, physical activity intensity has been inversely associated with fat mass in both men and women, ${ }^{35}$ whereas physical activity duration has been related to fat loss in men only. 35,36

Several hypotheses have been suggested to explain the gender differences in adaptations to exercise intervention. Boutcher and Dunn ${ }^{37}$ suggested that the changes may arise because men have a greater body weight and expend greater energy on physical activity than women. Alternatively, McMurray and Hackney ${ }^{38}$ determined that fat distribution and adipose tissue characteristics may differ by gender. Zouhal et al..$^{39}$ stated that intra-abdominal adipose tissue had a higher adrenergic response to physical activity in men, while Kuk and Ross ${ }^{40}$ showed that women had more loss of fat in the gluteal/subcutaneous zone, even though there was similar loss of fat in both genders. Importantly, weight loss enhances testosterone levels in men with obesity, ${ }^{41,42}$ and testosterone can increase lipolysis by induced-adrenergic down-regulated activity of lipoprotein lipase and triglyceride uptake in abdominal adipose tissue. ${ }^{30}$ Regardless of whether weight loss has occurred, exercise induces preferential loss of visceral fat in obese men. ${ }^{43}$

Another difference in weight loss between men and women is that men seem less concerned about their weight. ${ }^{44}$ According to
PubMed search results from the past to 2019, 5,961 studies have investigated the effect of weight loss programs in obese humans. Of these, 4,632 studies (77.7\%) were on females and 3,803 studies (63.8\%) were on males, showing that fewer studies have involved males. Although men are more susceptible to cardiovascular disease, ${ }^{45}$ they are less concerned with their weight, trying to lose weight, or taking part in weight-loss programs. ${ }^{46,47}$ Men generally perceive too many barriers and consider weight-loss programs as a "feminized realm." ${ }^{48}$ Moreover, few programs have been designed for men. ${ }^{49}$

Recently, some weight-loss programs have been designed to appeal specifically to men. ${ }^{50,51}$ In particular, to increase scalability, some have allowed exercise self-administration through written materials, messages such as short message service, videos, emails, or other resources instead of face-to-face interactions. Several studies have reported that such programs were successful for men. ${ }^{50,51}$ Therefore, to reduce male obesity, special weight-loss programs should be designed and applied specifically to men.

\section{CONCLUSION}

In regions where the prevalence of overweight men is higher than that of women, issues such as obesity type, hormones, awareness of body composition or shape, or special resources for exercise programs have rarely been considered. It is important to consider whether unhealthy increases in weight could be prevented, even when the argument is based on the result. To solve the problem of increased numbers of overweight and obsess males, integrated approaches are necessary; researchers must consider various sociodemographic characteristics and the physiological mechanisms related to obesity. Since the increasing trend of obese and overweight males has not been improved despite many attempts to address this issue, the underlying cause and treatment not merely addressing symptoms of male overweight and obesity must be investigated.

\section{CONFLICTS OF INTEREST}

The authors declare no conflict of interest. 


\section{ACKNOWLEDGMENTS}

The authors would like to thank the researcher in Sports Science Laboratory who helped with this work.

\section{AUTHOR CONTRIBUTIONS}

Review concept and design: KBK; drafting of the manuscript: all authors; critical revision of the manuscript: all authors.

\section{REFERENCES}

1. World Health Organization. Global Health Observatory (GHO) data: overweight and obesity, 2016 [Internet]. Geneva: World Health Organization; 2016 [cited 2020 Mar 6]. Available from: https://www.who.int/gho/ncd/risk_factors/overweight/en

2. Gray CM, Anderson AS, Clarke AM, Dalziel A, Hunt K, Leishman J, et al. Addressing male obesity: an evaluation of a groupbased weight management intervention for Scottish men. J Mens Health 2009;6:70-81.

3. Stibbe A. Health and the social construction of masculinity in Men's Health magazine. Men Masc 2004;7:31-51.

4. Gough B, Conner MT. Barriers to healthy eating amongst men: a qualitative analysis. Soc Sci Med 2006;62:387-95.

5. Seo MH, Lee WY, Kim SS, Kang JH, Kang JH, Kim KK, et al. 2018 Korean Society for the Study of Obesity guideline for the management of obesity in Korea. J Obes Metab Syndr 2019; 28:40-5.

6. Fan JG, Kim SU, Wong VW. New trends on obesity and NAFLD in Asia. J Hepatol 2017;67:862-73.

7. WHO Expert Consultation. Appropriate body-mass index for Asian populations and its implications for policy and intervention strategies. Lancet 2004;363:157-63.

8. Korea Centers for Disease Control and Prevention. Statistics for Korea National Health in 2017 [Internet]. Cheongju: Korea Centers for Disease Control and Prevention; 2019 [cited 2020 Mar 6]. Available from: https://knhanes.cdc.go.kr/knhanes/ eng/index.do

9. Thornhill R, Gangestad SW. The evolutionary biology of human female sexuality. New York (NY): Oxford University
Press; 2008.

10. Ley CJ, Lees B, Stevenson JC. Sex- and menopause-associated changes in body-fat distribution. Am J Clin Nutr 1992;55:950-4.

11. Palmer BF, Clegg DJ. The sexual dimorphism of obesity. Mol Cell Endocrinol 2015;402:113-9.

12. Min KB, Min JY. Android and gynoid fat percentages and serum lipid levels in United States adults. Clin Endocrinol (Oxf) 2015;82:377-87.

13. Guglielmi V, Sbraccia P. Obesity phenotypes: depot-differences in adipose tissue and their clinical implications. Eat Weight Disord 2018;23:3-14.

14. Pasquali R, Cantobelli S, Casimirri F, Capelli M, Bortoluzzi L, Flamia R, et al. The hypothalamic-pituitary-adrenal axis in obese women with different patterns of body fat distribution. J Clin Endocrinol Metab 1993;77:341-6.

15. Epel EE, Moyer AE, Martin CD, Macary S, Cummings N, Rodin J, et al. Stress-induced cortisol, mood, and fat distribution in men. Obes Res 1999;7:9-15.

16. Pasquali R, Anconetani B, Chattat R, Biscotti M, Spinucci G, Casimirri F, et al. Hypothalamic-pituitary-adrenal axis activity and its relationship to the autonomic nervous system in women with visceral and subcutaneous obesity: effects of the corticotropin-releasing factor/arginine-vasopressin test and of stress. Metabolism 1996;45:351-6.

17. Vicennati V, Pasquali R. Abnormalities of the hypothalamicpituitary-adrenal axis in nondepressed women with abdominal obesity and relations with insulin resistance: evidence for a central and a peripheral alteration. J Clin Endocrinol Metab 2000;85:4093-8.

18.Zumoff B, Strain GW, Miller LK, Rosner W, Senie R, Seres DS, et al. Plasma free and non-sex-hormone-binding-globulinbound testosterone are decreased in obese men in proportion to their degree of obesity. J Clin Endocrinol Metab 1990;71: 929-31.

19. Vermeulen A, Kaufman JM, Deslypere JP, Thomas G. Attenuated luteinizing hormone ( $\mathrm{LH}$ ) pulse amplitude but normal LH pulse frequency, and its relation to plasma androgens in hypogonadism of obese men. J Clin Endocrinol Metab 1993; 76:1140-6.

20. Isidori AM, Caprio M, Strollo F, Moretti C, Frajese G, Isidori A, 
et al. Leptin and androgens in male obesity: evidence for leptin contribution to reduced androgen levels. J Clin Endocrinol Metab 1999;84:3673-80.

21. Pasquali R, Vicennati V. Obesity and hormonal abnormalities. In: Björntorp P, editor. International textbook of obesity. Chichester: John Wiley \& Sons; 2001. p. 225-39.

22. Taylor RW, Grant AM, Williams SM, Goulding A. Sex differences in regional body fat distribution from pre- to postpuberty. Obesity (Silver Spring) 2010;18:1410-6.

23. Mongraw-Chaffin ML, Anderson CA, Allison MA, Ouyang P, Szklo M, Vaidya D, et al. Association between sex hormones and adiposity: qualitative differences in women and men in the multi-ethnic study of atherosclerosis. J Clin Endocrinol Metab 2015;100:E596-600.

24. Dhindsa S, Miller MG, McWhirter CL, Mager DE, Ghanim H, Chaudhuri A, et al. Testosterone concentrations in diabetic and nondiabetic obese men. Diabetes Care 2010;33:1186-92.

25. Allan CA, McLachlan RI. Androgens and obesity. Curr Opin Endocrinol Diabetes Obes 2010;17:224-32.

26. Arner P, Lithell H, Wahrenberg H, Brönnegard M. Expression of lipoprotein lipase in different human subcutaneous adipose tissue regions. J Lipid Res 1991;32:423-9.

27. Ramirez ME, McMurry MP, Wiebke GA, Felten KJ, Ren K, Meikle AW, et al. Evidence for sex steroid inhibition of lipoprotein lipase in men: comparison of abdominal and femoral adipose tissue. Metabolism 1997;46:179-85.

28. Cnop M, Havel PJ, Utzschneider KM, Carr DB, Sinha MK, Boyko EJ, et al. Relationship of adiponectin to body fat distribution, insulin sensitivity and plasma lipoproteins: evidence for independent roles of age and sex. Diabetologia 2003;46: 459-69.

29. Khaw KT, Barrett-Connor E. Lower endogenous androgens predict central adiposity in men. Ann Epidemiol 1992;2:675-82.

30. Grossmann M. Low testosterone in men with type 2 diabetes: significance and treatment. J Clin Endocrinol Metab 2011;96: 2341-53.

31. Michalakis K, Mintziori G, Kaprara A, Tarlatzis BC, Goulis DG. The complex interaction between obesity, metabolic syndrome and reproductive axis: a narrative review. Metabolism 2013;62:457-78.
32. King N, Byrne NM, Hunt A, Hills A. Comparing exercise prescribed with exercise completed: effects of gender and mode of exercise. J Sports Sci 2010;28:633-40.

33. Ismail I, Keating SE, Baker MK, Johnson NA. A systematic review and meta-analysis of the effect of aerobic vs. resistance exercise training on visceral fat. Obes Rev 2012;13:68-91.

34. Sanal E, Ardic F, Kirac S. Effects of aerobic or combined aerobic resistance exercise on body composition in overweight and obese adults: gender differences: a randomized intervention study. Eur J Phys Rehabil Med 2013;49:1-11.

35. Aadland E, Jepsen R, Andersen JR, Anderssen SA. Differences in fat loss in response to physical activity among severely obese men and women. J Rehabil Med 2014;46:363-9.

36. Aadland E, Robertson L. Physical activity is associated with weight loss and increased cardiorespiratory fitness in severely obese men and women undergoing lifestyle treatment. J Obes 2012;2012:810594.

37. Boutcher SH, Dunn SL. Factors that may impede the weight loss response to exercise-based interventions. Obes Rev 2009; 10:671-80.

38. McMurray RG, Hackney AC. Interactions of metabolic hormones, adipose tissue and exercise. Sports Med 2005;35:393412.

39. Zouhal H, Jacob C, Delamarche P, Gratas-Delamarche A. Catecholamines and the effects of exercise, training and gender. Sports Med 2008;38:401-23.

40. Kuk JL, Ross R. Influence of sex on total and regional fat loss in overweight and obese men and women. Int J Obes (Lond) 2009;33:629-34.

41. Niskanen L, Laaksonen DE, Punnonen K, Mustajoki P, Kaukua J, Rissanen A. Changes in sex hormone-binding globulin and testosterone during weight loss and weight maintenance in abdominally obese men with the metabolic syndrome. Diabetes Obes Metab 2004;6:208-15.

42. Hammoud A, Gibson M, Hunt SC, Adams TD, Carrell DT, Kolotkin RL, et al. Effect of Roux-en-Y gastric bypass surgery on the sex steroids and quality of life in obese men. J Clin Endocrinol Metab 2009;94:1329-32.

43. Ross R, Dagnone D, Jones PJ, Smith H, Paddags A, Hudson R, et al. Reduction in obesity and related comorbid conditions 
after diet-induced weight loss or exercise-induced weight loss in men: a randomized, controlled trial. Ann Intern Med 2000; 133:92-103.

44. Rolls BJ, Fedoroff IC, Guthrie JF. Gender differences in eating behavior and body weight regulation. Health Psychol 1991; 10:133-42.

45. Wirth A, Steinmetz B. Gender differences in changes in subcutaneous and intra-abdominal fat during weight reduction: an ultrasound study. Obes Res 1998;6:393-9.

46. Lemon SC, Rosal MC, Zapka J, Borg A, Andersen V. Contributions of weight perceptions to weight loss attempts: differences by body mass index and gender. Body Image 2009;6: 90-6.

47. French SA, Jeffery RW, Wing RR. Sex differences among participants in a weight-control program. Addict Behav 1994;19: 147-58.

48. Robertson C, Archibald D, Avenell A, Douglas F, Hoddinott P, van Teijlingen E, et al. Systematic reviews of and integrated report on the quantitative, qualitative and economic evidence base for the management of obesity in men. Health Technol Assess 2014;18:1-424.

49. Young MD, Morgan PJ, Plotnikoff RC, Callister R, Collins CE. Effectiveness of male-only weight loss and weight loss maintenance interventions: a systematic review with meta-analysis. Obes Rev 2012;13:393-408.

50. Morgan PJ, Callister R, Collins CE, Plotnikoff RC, Young MD, Berry N, et al. The SHED-IT community trial: a randomized controlled trial of internet- and paper-based weight loss programs tailored for overweight and obese men. Ann Behav Med 2013;45:139-52.

51. Young MD, Callister R, Collins CE, Plotnikoff RC, Aguiar EJ, Morgan PJ. Efficacy of a gender-tailored intervention to prevent weight regain in men over 3 years: a weight loss maintenance RCT. Obesity (Silver Spring) 2017;25:56-65. 